\title{
Introduction to Sexuality and Social Change: Toward an Integration of Sexuality Research, Advocacy, and Social Policy in the Twenty-First Century
}

\author{
Richard Parker
}

Over the course of the past 10 to 15 years, there has been an important increase in research activity and advocacy work on issues related to gender, sexuality, and health. Particularly following the emergence of the HIV/AIDS epidemic, funding available for research on sexuality and sexual health expanded significantly. Yet the vast majority of the research activity, as well as available funding for research, has been carried out from a biomedical perspective that has often failed to take into account significant social, cultural, economic, and political factors influencing the organization of gender and sexuality cross-culturally-and that has often failed to feed into meaningful advocacy for more effective policies and programs in relation to issues such as sexuality education and sexual health promotion.

Equally problematic in an increasingly globalized era, most research activities have continued to be conducted in economically developed countries. As a result, the complexity of issues related to gender, sexuality, and sexual health in highly diverse societies and cultures undergoing rapid and often unequal processes of social and economic development and change has remained largely unexplored. Even in economically developed settings such as the United States and the countries of Western Europe, where research on sexuality has been most intense and institutional support most pronounced, recent advances in the field have still largely failed to result in full-fledged, multi-dimensional, and multi-disciplinary research agendas for the study of sexuality. Absent also has been a clear conception of the ways in which such agendas might provide the basis for more effective programmatic interventions or feed into and stimulate public dialogue, debate, and policy regarding sexual rights, sexuality education, and sexual and reproductive health in relation to such key concerns as community development, social justice, and human rights.

A number of different initiatives over the course of recent decades have sought to address this situation. Particularly in the late 1980 s and the early 1990s, research support and training on the part of the World Health Organization's (WHO) Global Programme on AIDS, as well as by the WHO's Special Programme of Research, Development, and Research Training in Human Reproduction, provided important incentives for international initiatives that helped to stimulate research on sexual health in many countries, and to link such research to practical and applied programmatic goals. In addition, as the study of reproductive health has developed as a field over the course of the 1990s, drawing important support not only from intergovernmental agencies, but also from a number of important private and non-governmental donors, such as the John D. and Catherine $\mathrm{T}$. MacArthur Foundation, the Rockefeller Foundation, and the Ford Foundation, increased funding has begun to become available for both research and training in this field in many different settings (see di Mauro, 1995; Parker, 1997).

The Ford Foundation, in particular, has played a

Correspondence concerning this article should be addressed to Richard Parker, Department of Sociomedical Sciences, Mailman School of Public Health, Columbia University, 722 West 168th Street, 9th Floor, New York, NY 10032. E-mail: rgp11@columbia.edu 
key leadership role in providing support for research, policy dialogue, and advocacy related to sexuality, sexual rights, and sexual health, stimulating sexuality research training activities and the development of sexuality research projects and programs in the United States as well as through many of its field offices in developing countries. The Sexuality Research Fellowship Program at the Social Science Research Council (see di Mauro, 2002), as well as the US national sexual behavior survey carried out in the 1990 s by researchers associated with the University of Chicago (Laumann, Gagnon, Michael, \& Michaels, 1994) are examples of this work, as are a new series of initiatives such as the founding of regional Sexuality Resource Centers in Africa, Asia, Latin America and North America, including the National Sexuality Resource Center (http://nsrc.sfsu.edu) at San Francisco State University, and the Center for Gender, Sexuality and Health at Columbia University. Like Ford, the Rockefeller Foundation has played an important role through its support for innovative new programs such as the work of CLAGS (http://web.gc.cuny.edu/clags/index.html), the Center for Lesbian and Gay Studies, at the City University of New York and the Program in Gender and Sexuality, Health and Human Rights (http://www.cumc .columbia.edu/dept/sph/cgsh.html) at Columbia University. Such initiatives have opened up new possibilities for sexuality research and theorizing outside of the traditional frame of biomedically driven health-related research, and have consistently sought to articulate research activities and research findings with the work of the diverse social movements that have staked a claim in relation to gender and sexuality: in particular, the feminist, international women's health, and reproductive rights movements; gay, lesbian, bisexual, and transgender movements; HIV/AIDS activists; and, increasingly, the international human rights movement.

Other signs of changing times in the sexuality research business can be found in the recent boom in the publication of books, edited volumes, and academic journals focusing on the social dimensions of sexuality, as well as the development of new training opportunities based at academic centers and the establishment of new professional associations. In the late 1990s, for example, we saw the launch of important new journals such as Sexualities (edited by Kenneth Plummer from Essex University, and published by Sage [http://www.sagepub.com/journal.aspx?pid=200]) and Culture, Health and Sexuality (edited by Peter Aggleton from the University of London, and published by Taylor \& Francis [http://www.tandf. co.uk/journals/titles/13691058.html]). During this same period, established academic sexuality journals, such as the Archives of Sexual Behavior (edited by Kenneth Zucker at the University of Toronto and published by Kluwer Academic/Plenum Publishers for the International Academy of Sex Research [http://reo.nii.ac.jp/journal/HtmlIndicate/html/vol is sues/SUP0000001000/JOU0001000037/vol issue li st.html]) and The Journal of Sex Research (edited by John D. DeLamater, and published by Society for the Scientific Study of Sexuality) sought to remake themselves and broaden their approaches to include more social and cross-cultural research.

New summer institutes on sexuality emphasizing the social and cultural dimensions of sexuality were founded at academic institutions such as the University of Amsterdam (http://www.ishss.uva.nl/ SummerInstitute) and San Francisco State University (http://hmsx.sfsu.edu/summerinstitute).

Undergraduate degree programs (or at least areas of emphasis) in fields such as gay and lesbian studies have become increasingly common in Western Europe and North America, and post-graduate training programs such as the Masters of Art in Sexuality Studies at San Francisco State University (http://hmsx.sfsu.edu/ education/graduate/index.html) and the Masters of Public Health Track in Sexuality and Health at Columbia University (http://cait.cpmc.columbia .edu:88/dept/sph/sexhealth-track.html), also began to emerge during the past decade. Building on the foundation provided by funding available for HIV/AIDS research, post-doctoral training initiatives, including the Training Program at the HIV Center for Clinical and Behavioral Studies of the Department of Psychiatry at Columbia University (http://www.hivcenternyc.org/training/tra bigf.html) have made gender and sexuality the primary focus of their training activities, and new academic positions in a wide range of disciplines and departments have 
begun to advertise for and hire researchers specializing in sexuality. Equally important, the founding of new professional associations, such as the International Association for the Study of Sexuality, Culture and Society (IASSCS), provided an alternative (or at least a complement) to more traditional sexological and biobehavioral approaches in the field. In almost all cases, these initiatives have been developed in important ways in direct relation to social movements and new social configurations that are involved in the broader progressive struggle in defense of sexual rights, sexuality education, and sexual health promotion as issues of human rights and social justice in the early twenty-first century.

Yet as important as these recent developments have been, it is clear that there is still much that must be done in order to build upon the activities initiated over the course of recent decades and to develop a new agenda for research and action on sexuality in the twenty-first century. This has become all the more evident recently as a range of sexuality initiatives have come under attack, particularly in the United States. Since the election of the George W. Bush administration in the United States in 2000, we have seen a growth in the number of interventions against what are perceived to be undesirable examples of sexuality research and programming, particularly against those that are supportive of sexual diversity or of framing sexual rights as questions of social justice. During 2003, for example, in the United States there have been widespread reports of politically motivated interference with the scientific review process at the National Institutes of Health (NIH), as well as of audits related to both research studies and program implementation supported by funds from NIH or from the Centers for Disease Control (CDC) (Goode, 2003; Kaiser, 2003; Kristof, 2003). Indeed, a veritable research and advocacy industry supported by conservative funders and organizations seems to have grown up, particularly in the form of non-governmental organizations and right-wing "think tanks," but also in some academic settings, with the apparent goal of marshaling selective scientific evidence with regard to issues such as the perceived negative effects of nontraditional families, the efficacy of abstinence-only education, the lack of efficacy of condom use for sexually-transmitted disease prevention, and other similar topics (Girard, in press).

Although the long term consequences of such initiatives remain to be seen, at least one thing seems clear: while the field of sexuality studies has grown in important ways over the course of the 1990 s and the beginning of the current decade, providing greater support for a range of activities that might well contribute to progressive changes in policies and politics related to sexuality, sexual rights, sexuality education, and sexual health promotion, there can be little doubt that this work has failed to influence social policy creation as directly and profoundly as have the proponents of a more conservative agenda for both research and action. In fact, while policy-related work carried out from more progressive perspectives has continued to largely ignore sexuality as a field of struggle and sexuality research as a potential source for empirical data and grounded analyses that might contribute to policy debates, many conservative groups have become particularly adept in recent years in making sexuality a central focus for their activities. In light of this trend, together with the apparent efficacy with which extreme right-wing advocates have managed to influence policy at every level, the importance of articulating a more meaningful engagement between sexuality research and advocacy aimed at defending sexual rights and social justice concerns has become essential. A new focus on linking contributions of the growing field of sexuality research to the social policy debates currently raging in the United States, but also taking place globally in an increasingly interconnected world, has emerged as one of the most important challenges currently confronting us.

The launch of this new electronic journal, Sexuality Research and Social Policy: Journal of $N S R C$, edited by Gilbert Herdt and developed as a key strategic initiative of the National Sexuality Resource Center at San Francisco State University, marks an important milestone in the development of this field, and is a major step forward in seeking to develop a progressive response to the increasingly bold incursions of conservative extremists (so often armed with pseudo-scientific data) in relation to sexuality and social policy in the United States as well as abroad. By 
consciously seeking to articulate sexuality research findings with advocacy in relation to more enlightened and informed policies and programs, this new journal offers the possibility of bringing both theoretical and conceptual work, as well as empirical research findings, to bear on a range of cutting edge social policy debates that are currently raging in a variety of diverse forums and contexts around the world.

In this inaugural issue of Sexuality Research and Social Policy: Journal of NSRC, for which I am honored to have been invited to serve as guest editor, our overarching goal is to begin to advance a research agenda for sexuality that is geared towards advocacy, effective policy formulation, and social and political intervention in relation to sexual rights, sexual health promotion, and sexuality education. There are several important principles that inform and guide this work, and that are central to the various papers that have been brought together in this issue:

First among these principles is the conviction that sexuality cannot be understood apart from the political/economic/social structures within which it is embedded-without reference to cultural and ideological discourses that give it meanings. This has long been one of the guiding principles of research focusing on the social dimensions of sexuality, but becomes even more important as we seek to move from research in and of itself to a more profound interconnection between research and advocacybetween theory and practice (see Parker, Barbosa, \& Aggleton, 2000; Parker \& Gagnon, 1995).

Second, while the relationship between sexuality and health is crucially important, if we are to truly advance our understanding of this relationship, we must urgently expand our frame of reference beyond understanding and conceptualizing sexuality as nothing more than a sexual health problem. An alternative, and perhaps potentially more fruitful, way of thinking about the range of social and political problems associated with sexuality is to adopt the human rights framework, within which it is still possible to address important health concerns, but as part of a broader conception of sexual and reproductive health and rights (see Parker et al., 2000; see, also, Petchesky, 2003).

Third, dialogue concerning sexuality policy cannot be limited to those who do research on sexuality, but must be broadened to include providers, advocates, and others whose work encompasses sexuality in some fashion. In addition, many researchers in other fields, such as economics, politics, and history, do not currently conceive of their work as within the framework of sexuality, but could be encouraged to see the implications of their work for sexuality (see, for example, Petchesky \& Judd, 1998).

Fourth, we must realize that there are several distinct types of research that affect sexuality policies. In some instances, a researcher may specifically intend to influence policy. In other circumstances, the researcher does not explicitly set out to reach policy makers, but her or his results can be utilized by others to affect policy. Finally, there may be studies of the policy process itself. All of these different forms of research, and the approaches to research activity that result from them, must be included and applied to the many pressing issues regarding sexuality that currently confront us.

Public dialogue is an indispensable element in the research/policy/advocacy triangle, precisely because policy makers are beholden to their constituents, at least in countries which have some sort of representative government. In order to understand the dynamics involved in the development of sexuality policy, it is essential to examine the interconnections among research on sexuality, advocacy initiatives, and social policy (see Figure 1). This diagram shows how research on sexuality influences and is influenced by advocacy initiatives, in which scholars and activists produce knowledge that can be employed to further both research agendas and advocacy of sexual rights. A mechanism by which research findings on sexuality influence social policy indirectly is when advocates use these findings to strengthen their claims to policy makers (whether on their own initiative or at the request of policy makers). Research on sexuality also has the potential for influencing social policy directly, when policy makers commission research papers and when scholars lobby to be listened to by policy makers. Social policy also influences the research agenda concerning sexuality by helping to shape the funding mechanisms, shifts in resources, research interests of agencies, and distribution of human and economic 
capital in academic as well as in applied research settings.

In carrying out such work, at the interface of research, advocacy, and policy formation, it is important to remember that even if we adopt a human rights approach, we must be conscious of the need to interrogate the human rights frame in terms of the is needed.

There is also a need for investment in a better understanding of the process of policy development itself at all organizational levels. This requires particular exploration of the disjunctures that emerge in the collision within and among local, national, and global agendas regarding sexuality. In addition, it is

Figure 1. Interconnections among research on sexuality, advocacy initiatives, and social policy in the context of funding agencies

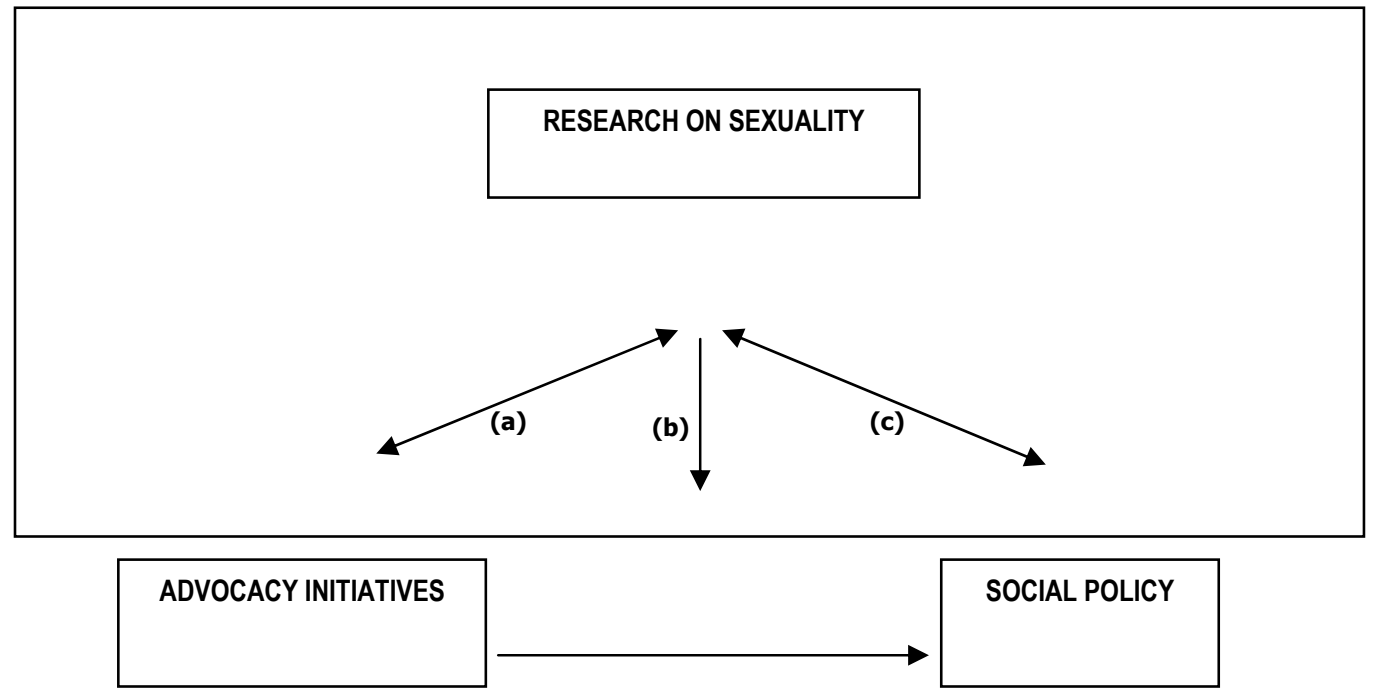

social construction of rights. For example, are human rights just protections or are they state duties? What are the implications of the distinction between having a right and truly having the ability to exercise it? We must acknowledge the remarkable complexity of seeking to reconcile various local, national, and global human rights discourses into a single frame (especially as they vary in their conceptions of international instruments of human rights, legal and judicial processes, and claims to cultural specificity). While the term "sexual rights" has sometimes been used to denote the field of sexuality more broadly, this is nonetheless problematic precisely because this area is so under-theorized (e.g., there have not been enough studies about it) and underdeveloped (e.g., there is not a shared definition even among the most sophisticated advocates). Precisely because of this, more discourse and agreement on the uses and meanings of such terms necessary to study the actors in these policy development processes, including both conservative and progressive social movements, political parties, lobbying groups, and businesses. A critical but often overlooked point is that many types of policy-in economic, political, social, and other areas-affect sexuality, whether intentionally or unintentionally, directly or indirectly.

It is crucial to gain greater insight into the multiple ways that advocacy groups are successful (or not successful) in influencing policy outcomes. Research on the effects of advocacy on sexuality policy is needed. At the same time, we also need to problematize any assumption that the influence of advocacy groups is easily measurable in quantitative terms, or in the short run. Nor should we assume that successful models of influence in one place are directly transportable to other settings. 
To advance the agenda of sexuality and social policy research and advocacy, it is also imperative to foster a better understanding of sexual cultures at the local, national, and global levels, and of the myriad various social elements that shape those cultures, such as the mass media, gender inequality, social movements (on the right, left, and in the middle), economic shifts, population migration, globalization, and legacies of historical events. Above all, we must recognize that major obstacles exist, particularly in the current political conjuncture, which pose serious challenges for this work: there are hegemonic cultural, political, and religious ideologies that limit (and in many circumstances prohibit) public debate and curtail critical investigation of sexuality policies. Advancements in the field are hindered by a lack of resources and human capital in all arenas of sexuality research and advocacy. Dialogue and informationsharing among scholars about sexuality, among different sectors in society, including researchers, advocates, and policy makers, and across nations are limited and insufficient. Lack of information dissemination is also a serious problem, and all too often, research findings are circulated only within research institutions, and the communities from which data were extracted never have access to them.

It is at the point of intersection of these various dilemmas and challenges that this new journal may be able to play such an important role. By focusing on the dynamic interplay between sexuality research, progressive advocacy, and contemporary social policy debates, we hope that Sexuality Research and Social Policy: Journal of NSRC will be able to make a key contribution in seeking to develop a progressive response to the reactionary trends that have characterized so much recent debate on sexuality and policy. By engaging with the information age (Castells, 1996), and launching Sexuality Research and Social Policy: Journal of NSRC as an electronic journal, using rigorous peer review processes but with an electronic format that should be more agile than traditional print publishing venues, this new journal hopes to directly address one of the key difficulties identified in the dissemination of research findings and empirical evidence that will be so necessary for more effective advocacy work.
In this first special issue of Sexuality Research and Social Policy: Journal of NSRC, we are especially fortunate to have assembled a particularly stellar cast of contributors whose work has already made major contributions toward furthering the impact of sexuality research on social policy formation. While they examine a wide range of different issues, the articles that have been brought together here all seek to further our understanding of the complex interrelationship between sexuality and social change in the contemporary world.

"Sexuality, Human Rights and Demographic Thinking: Connections and Disjunctions in a Changing World," by Sonia Corrêa and Richard Parker, explores the recent evolution of global debates linking sexuality and human rights. It identifies a number of conceptual problems that need to be confronted in these debates and explores the implications of these problems for international public dialogue in relation to gender, sexuality, and HIV/AIDS.

Gilbert Herdt's contribution, "Sexual Development, Local Culture, and Social Oppression," focuses on the extent to which much of the research carried out on human development and on childhood and adolescent sexuality has failed to examine the importance of cultural meaning systems, and on how the socially constructed elements of the life course, especially in relation to sexual inequality, social oppression, and social and cultural change, serve to shape sexual experience. In particular, he calls our attention to the importance of resilience-even in the face of domination and discrimination-in sexual development, and to the need for linking sexuality research more effectively to policy debate and formation in order to stimulate greater resilience and to resist all forms of oppression.

In "Sexuality and Globalization," Dennis Altman describes the ways in which complex processes of social, cultural, political, and economic globalization impact upon sexuality (and are impacted by it) by opening up new forms of inequality and oppression, but also by creating new forms of resistance and new opportunities for personal redefinition. He focuses on the social challenges related to HIV/AIDS, the construction of sexual identity, and the emerging struggles for sexual rights in countries and cultures 
around the world as key domains in which gender and sexuality are being reconfigured within the broader context of social and economic change that is taking place as a result of increasingly rapid globalization.

Many of these same themes resonate, yet with a different inflection, in Gary W. Dowsett's article, "Baring Essentials: Science as Desire," which focuses on the ways in which the rise of new technologies is reshaping sexuality and explores the relevance of these changes for sexuality research. Through an examination of the changing material (and virtual) realities in which sexuality is invented and reinvented, Dowsett pushes us to address the role of the body and its practices in the constitution of sexual experienceand in so doing, to more fully realize the promise of a truly social (as opposed to individualized) construction of sexuality in the twenty-first century.

Many of these same theses are examined in "Expanding and Making Flexible Normative Patterns of Sexuality among Young People,” by Vera Paiva, José Ricardo Ayres, and Ivan França Jr., which explores the implications of such a perspective for interventions designed to promote the sexual citizenship and sexual rights of young people. These authors seek to problematize the normative assumptions that young people must confront, and thereby to open up the possibilities for a kind of dialogical reflexivity that can lead to a new flexibility in normative patterns.

While the contents of this first special issue of Sexuality Research and Social Policy: Journal of NSRC only scratch the surface of the many complex issues that currently confront us as we seek to advance the field of sexuality research, to make new connections between sexuality researchers and advocates, and to contribute to more effective and socially progressive policy formation, we hope that these articles will serve to introduce readers to the types of analysis as well as the political commitment that they can hope to find in this journal in the future. In addition, I personally hope that these articles will serve as an invitation to all who wish to take up this debate and to contribute to the ongoing struggle to link sexuality research and advocacy to the principles of human rights and social justice for all.

\section{Acknowledgments}

The majority of the articles included in this special issue, and much of the thinking behind it, were developed for a conference supported by the Ford Foundation and organized by ABIA (the Brazilian Interdisciplinary AIDS Association) and the Program on Gender, Sexuality and Health in the Institute of Social Medicine at the State University of Rio de Janeiro in December of 200o. Special thanks are due to Dennis Altman, Pimpawun Boonmongkon, Amanda Claremon, Sonia Corrêa, Steve Epstein, Juan Guillermo Figueroa, Angela Freitas, Ana Luisa Liguori, and Miguel Muñoz-Laboy, who participated in the conference working group on sexuality, policy and public dialogue, and whose report helped to frame many of the issues included here, and to Giang Minh Le, who helped to work through and systematize conference proceedings. Special thanks as well to Sarah Costa and to the Ford Foundation for their commitment and their on-going support of this work.

\section{References}

Castells, M. (1996). The rise of the network society (The information age: Economy, society and culture, volume 1). Oxford, England: Blackwell Publishers.

di Mauro, D. (1995). Sexuality research in the United

States. New York: Social Science Research Council.

di Mauro, D. (2002). Current trends and future directions in sexuality training. In D. di Mauro, G. Herdt, \& R. Parker (Eds.), Handbook of sexuality research training initiatives. New York: Social Science Research Council.

Kaiser, J. (2003). Studies of gay men, prostitutes come under scrutiny. Science, 3oo(18), 403.

Kristof, N.D. (2003, May 9). No time to get squeamish. The New York Times. Retrieved May 9, 2003, from http://www.nytimes.com/2003/05/09/ opinion/ gKRIS.html

Girard, F. (in press). The Bush kamasutra: Implications of American domestic and international positions and policies on sexuality (Working Paper No. 1, International Working 
Group on Sexuality and Social Policy). New York: Center for Gender, Sexuality and Health, Columbia University. Unpublished manuscript.

Goode, E. (2003, April 18). Certain words can trip up AIDS grants, scientists say. The New York Times. Retrieved April 18, 2003, from http://www. nytimes.com/2003/05/09/opinion/9KRIS.html

Laumann, E., Gagnon, J., Michael, R., \& Michaels, S. (1994). The social organization of sexuality: Sexual practices in the United States. Chicago: The University of Chicago Press.

Parker, R.G. (1997). International perspectives on sexuality research. In J. Bancroft (Ed.), Sexual behavior: Methodological issues (pp. 9-22). Bloomington, IN: Indiana University Press.

Parker, R.G., \& Gagnon, J.H. (Eds.). (1995). Conceiving sexuality: Approaches to sex research in a postmodern world. New York: Routledge.

Parker, R., Barbosa, R.M., \& Aggleton, P. (Eds.). (2000). Framing the sexual subject: The politics of gender, sexuality and power. Berkeley, CA: University of California Press.

Petchesky, R.P. (2003). Global prescriptions: Gendering health and human rights. London: Zed Books.

Petchesky, R.P., \& Judd, K. (Eds.). (1998). Negotiating reproductive rights: Women's perspectives across countries and cultures. London: Zed Books. 